\title{
Examining Reading Alouds in Preschool Education Classrooms in Turkey
}

\author{
Şeyda Deniz Tarım ${ }^{1}$ \\ ${ }^{1}$ Faculty of Education, Muğla Sitkı Koçman University, Muğla, Turkey \\ Correspondence: Şeyda Deniz Tarım, Faculty of Education, Muğla Sitkı Koçman University, Muğla, Turkey, 48000.
}

Received: September 11, 2015

Accepted: September 24, 2015 Available online: September 30, 2015

doi:10.11114/ijsss.v3i6.1082

URL: http://dx.doi.org/10.11114/ijsss.v3i6.1082

\begin{abstract}
This study described and examined how reading alouds were carried out in 17 public preschool classrooms in Muğla, Turkey through detailed ethnographic field observations using the OMLIT-RAP that identifies and rates teacher behaviors when reading aloud to children. How often read-alouds performed during the week? How long were they? Did dialogues and follow-up activities occur? The results indicated that the quality of reading alouds in public preschool classrooms in Muğla - to be of low-to-moderate degree. Based on the findings of this study, other ways of improving reading alouds can be pinpointed, such as giving one or two vocabulary and accurate comprehension support for each word, having all children join in conversations with teachers during read alouds, expanding on children's comments about the book, placing the book in the context by mentioning the classroom theme or how the book fits into class activities and extending children's understanding by tapping into their own experiences to help them comprehend the story.
\end{abstract}

Keywords: Emergent literacy, reading, books, preschool children, Turkey

\section{Introduction}

Guiding this study is the social interactionist approach built upon cultural psychology (e.g., Vygotsky, 1978), that focuses on the culturally rich environments in which children live as mediators of learning. From this perspective, emergent literacy skills are understood as supported through social interaction with exposure to high-quality teaching practices (Neuman \& Cunningham, 2009) and rich literacy materials (Sulzby \& Teale, 1991).

Recent studies on reading to young children demonstrate that it is crucial experience for developing children's early language and literacy skills. The increasing emphasis on improving reading alouds in preschool classrooms has led researchers to question various characteristics of these reading routines such as how often do teachers read in classrooms; how do they engage children in conversation and extend their comments about books and more importantly, the quality of interactions between teachers and children during reading aloud activities, known to influence the development of children's early literacy skills (Whitehurst \& Lonigan, 1998; Neuman \& Roskos, 1993; Roskos \& Neuman, 2001; Neuman \& Dickinson, 2001; Neuman, Hood, Ford \& Neuman, 2011; Neuman, Hood, \& Ford, 2013; Zucker \& Landry, 2010).

Previous studies suggest that effective early childhood educators should be knowledgeable about language and literacy development (Dickinson \& Brady, 2006; Neuman \& Cunningham, 2009) and they should also know how to put content knowledge into practice. Further, as Neuman and Cunningham (2009) state, "[the teachers] need to understand what individual children bring to learning, their cultural histories, building upon their prior in a way that engages children's understanding in meaningful literacy practices (Neuman \& Cunningham, 2009, p. 553). Based on the literature, it is obvious that quality teaching has a key role in children's early literacy development.

Consequently, the current study concentrates on one component of language and literacy curriculum, read alouds, and examines daily classroom read alouds while focusing on teacher behaviors. This research is also based on the premise that improvements in teachers' classroom practices may hold great promise for improving the quality of early literacy teaching and practice for preschoolers.

Before discussing the previous studies on read alouds in preschool classrooms in the following section, it is appropriate to define the term "read-aloud" and then provide a brief discussion of previous studies on read alouds in preschool classrooms. "Read-aloud" has been defined as a dynamic process influential on children's oral and print language development in which "an adult and a child or children sharing a book together" (Zucker and Landry, 2010, p. 79). 


\subsection{Previous Studies on Read Alouds in Preschools}

The literature has variously described high-quality reading alouds as comprising various essential dimensions including supporting extended discussion of a book (Dickinson and Smith, 1994); aiming better comprehension while enriching vocabulary (Beck \& McKeown, 2007; Justice, Meier, \& Walpole, 2005); developing print knowledge and phonological awareness (Mol, Bus, \& de Jong, 2009); supporting oral language and early writing through the use of post-reading activities (Zucker and Landry, 2010) and setting up a pleasant, comfortable reading aloud context in an appropriate time of the day (Morrow, 1998; Morrow and Smith, 1990).

Recent studies showed that children's vocabulary grow when teachers provide rich explanations of words to children during read alouds in classrooms (Beck \& McKeown, 2007; Justice, Meier, \& Walpole, 2005). As researchers suggest teachers should plan carefully and focus on multiple words in each read aloud to develop children's vocabulary. Further, read alouds support children's both "literal and inferential" thinking skills to understand text; while literal language refers to concrete things (e.g., color, shape), inferential language refers to abstract things (e.g., feelings) that are not part of immediate environment (Zucker and Landry, 2010, p. 82). The previous studies show that both literal and inferential language development are essential aspect of vocabulary growth. Thus, in order to support children's use of literal and inferential language, teachers can engage children in read alouds by asking questions starting with simple answer questions to open ended ones that elicit more information from children (Justice, Meier, \& Walpole, 2005; Zucker and Landry, 2010).

Furthermore, read alouds also develop children's print knowledge and phonological awareness. There is considerable research showing that positive effects were found on both children's print knowledge (National Early Literacy Panel, 2008) and phonological awareness (Mol et al., 2009) when teachers direct children's attention to print or letters during read alouds through various activities such as pointing to letters or identifying rhymes and repeating sounds that they hear from the book.

Previous studies also demonstrate that post-reading activities related to the book have significant effects on children's oral language and writing awareness. Post- reading activities are often defined as extensions to support children's learning with using vocabulary activities, drama activities or drawing activities (Zucker and Landry, 2010). As the researchers pinpointed, "to make story extension activities useful for children's language development, teachers should ask open-ended questions and elaborate on children's responses, build text or theme vocabulary or make connections related to the book" (Wasik, Bond and Hindman, 2006 cited in Zucker and Landry, 2010) and to the real world. Therefore, preschool teachers should embrace a perspective that does not consider reading alouds as routine activity but as an important step in the creation of a foundation for children's engagement in words as well as in the world (Damber, 2015).

What is more, read aloud context (e.g., group size, book choice, amount of time) is also found influential on children's learning (Morrow, 1988; Mol et al., 2009). Although Morrow and Smith (1990) suggest that children can ask more questions to teachers or get more responses back from teachers in small-group settings, controversial research findings were seen in different studies. Mol et al., discussed that large group reading aloud sessions may also be seen beneficial for children's learning. Further, according to Zucker and Landry (2010), researchers also have different views on the amount of time preschoolers should spend in reading alouds. However, more time spent in reading alouds is seen necessary.

\subsection{Context of the Study}

Currently, about 40 percent of preschool-age children in Turkey attend preschool programs, in spite of the fact that preschool education is not compulsory. The annual growth observed in preschool attendance can be attributed to the many national-level initiatives to expand enrollment and provide high quality preschool education in Turkey. One of the major efforts targeting high quality preschool education is revising 1989's academic-oriented early childhood curriculum and launching a new developmental curriculum in years of 1994, 2002 and 2006. As more research has focused on the implementability of the program objectives and the developmental areas targeted and prioritized in the curriculum, curriculum practitioners or administrators evaluated and updated the early childhood curriculum in 2013.

In the updated curriculum of 2013, it has been emphasized that in pre-primary education classrooms in Turkey formal reading and writing instruction are not provided but considering that children's early language and literacy skills are an indicator of school readiness and formal reading achievement, their development should be supported before children enter primary school. Therefore, twelve objectives (e.g., developing vocabulary, displaying print awareness, and knowledge of sounds) and indicators are defined in the area of language development and samples of language activities that support children's early language and literacy skills are given. However, more detailed instruction and concrete knowledge of each objective in the area of language development has been neglected. For instance, the curriculum explains what a teacher does during interactive reading time briefly, but a more standardized and comprehensive model 
of interactive reading time (e.g., what to do before reading, during reading or post reading) should be provided.

Overall, studies that increase the understanding of the quality of early literacy practices in preschool classrooms in Turkey are timely and warranted; therefore, the present study aimed to contribute to the literature by examining the quality of reading alouds in randomly selected preschools in the province of Muğla in the Aegean Region of Turkey.

\section{Method}

\subsection{Participants}

This study was conducted with 17 randomly selected MoNE-affiliated public preschools in the central district of Muğla. After receiving official written permission from the MoNE provincial directorate, the researcher met with principals and teachers from the selected schools to explain the study objectives and the classroom observations involved in order to determine their willingness to participate in the study.

The safeguards to protect the identities of the schools and individuals participating in the study were also explained; namely: all data collected would be stored electronically in password-protected documents accessible only to the researcher; data would be shared only with students and other researchers for educational purposes; and no names or any other information that could be used to identify the schools or teachers involved would be used in any written report associated with this research.

After obtaining permission from principals and teachers, data was collected from 17 preschool classrooms in 17 preschools through classroom observations of reading aloud sessions, particulary teachers' behaviors. Each preschool classroom was visited three to four times for all day long over one academic year, during which extensive field notes were taken. Observations were scheduled for days when there were no field trips or other special events planned and when the teacher was expected to be present. The data collection was conducted by the author and a trained research asisstant. The research assistant were $\mathrm{PhD}$ candidate who were working in the field of educational research.

The participants were all females and had an average of ten years' experience ranging from 4 to 25 years. Most of the teachers had a 4-year college degree and almost ten percent had an associate's degree. There were about 15-18 preschool children in the observed classrooms.

\subsection{Data Collection Tool}

The OMLIT was developed as a battery of measures to address the need for reliable, research-based measurement of instructional practices and environmental support for language and literacy in the early childhood classroom (Goodson, Layzer, Smith, \& Rimdzius, 2006). The OMLIT includes six instruments: Classroom Description, Snapshot of Classroom Activities (SNAPSHOT), Read-Aloud Profile (RAP), Classroom Literacy Instruction Profile (CLIP), Quality Rating of Language and Literacy Instruction (QUILL) and Classroom Literacy Opportunities Checklist (CLOC).

This study was conducted using the OMLIT-RAP, a description of teacher behavior when reading aloud to children. The RAP records adult behavior during the read-aloud session in three categories: (1) pre-reading (set-up) behavior, (2) behavior while reading the book, (3) post-reading behavior. The RAP also records: (1) role of the adult involved in the read-aloud (e.g., teacher, aide, etc.), (2) characteristics of the book being read, and (3) number of children involved in the read-aloud. The RAP also includes three quality indicators that summarize particular aspects of the read-aloud: (1) the degree to which the adult introduces and contextualizes new vocabulary to support children's learning; (2) the extent to which the adult uses open-ended questions that invite children to engage in prediction, imagination, and/or rich description; and (3) the quality and length of any post-reading book-related activities that the adult organizes (beyond oral discussion).

It is reported by the OMLIT-RAP's authors that an agreement on instructional behavior across the entire book reading (before, during, and after reading a book) was 90 percent. For the quality indicators, average inter-rater reliability was 84 percent agreement for exact matches between the ratings given by the two coders.

\subsection{Data Analysis}

This is a qualitative study in terms of the type of data used and the descriptive analysis conducted. After each preschool classroom was observed, the classroom's reading aloud profile was rated on a 5 point scale (minimal to high) under the domains (e.g., instructional strategies and quality indicators) as described above. Under each domain, there are 10-13 clearly defined teacher behaviors during read alouds.

Prior to the collection of data, inter-observer agreement was obtained using the observation measure, OMLIT-RAP. Interrater reliability data for the OMLIT-RAP were gathered throughout the data collection period on approximately $20 \%$ of the preschool classrooms. The author and the research assistant rated these classrooms' reading aloud profiles. Percent agreement for the reliability checks (computed by dividing the number of agreements by the number of agreements plus disagreements) ranged from $85 \%$ to $95 \%$ all components of the measure (Table 1). 
Table 1. Inter-Rater Agreement on the Read Aloud Profile (OMLIT-RAP)

\begin{tabular}{ll}
\hline Codes & Average \% Agreement \\
\hline Instructional Strategies & 85 \\
Pre-reading strategies used by teacher & 87 \\
Reading strategies used by teacher & 95 \\
Post-reading strategies used by teacher & \\
Quality Indicators & 85 \\
Vocabulary links & 87 \\
Adult use of open ended questions & 90 \\
Depth of post-reading activities & \\
\hline
\end{tabular}

\section{Results}

\subsection{Overview of Reading-Aloud Sessions in Classrooms}

This part is planned to give the main features and the patterns of the reading alouds in the preschool classrooms that emerged from the data.

Depending on the data, the majority (13/17) of preschool classrooms featured a layout designed to facilitate whole-group reading aloud session. Almost every classroom included a large rug capable of accommodating all the children in the classroom and had enough space, they still appeared overcrowded, with materials stacked in such a way as to be inaccessible, and unpleasant odors were noted during the observations.

All classrooms had plenty of books, and all but 5 classrooms had a separate, distinct reading area containing books that children could choose from. However, these reading areas were modest, able to accommodate at most 2 children at a time. Reading areas were generally observed to be part of the circle area with a cabinet or basket of between 8-20 books close to the area, but the reading areas lacked soft furnishings such as pillows, cushions or couches that would render them more appealing. Moreover, while the books accessible to teachers were in good conditions, most of the books accessible to children, unfortunately, were in relatively poor condition with torn pages, missing covers or faded print and included only one or two genres, usually stories or instructional books for cooking and toy-making. None of the booksacks contained poetry, science, history or other non-fiction magazines or books. Finally, the books accessible to children were not geared to a wide range of reading and comprehension levels from very easy to challenging.

The data indicated that in most of the classrooms reading occurred on a regular basis, mainly once a day, generally before lunch - sometimes as part of Turkish Language activities following rhyming, songs - or in the afternoon right before they go home.

The most common length of reading sessions was between ten to fifteen minutes, with a minimum of 4 minutes and a maximum of 25 minutes. In almost every reading aloud session, took place in the preschool classrooms, was a stand-alone activity, without linking to other classroom activities taking place during classroom hours. Even if reading aloud sessions took place as part of Turkish Language activities, the books or texts read to the children were not carefully planned related with the classroom curriculum or seem connected to particular sounds in the rhymes, or finger plays aimed to stimulate children's phonological awareness.

A pattern of allowing the children to choose books for reading did not emerge at all. The teachers always chose the books for reading time and took the initiative of reading alouds. Unfortunately, the behavior patterns of teachers displayed that choices of books were mostly coincidental although some of the reading aloud sessions were part of Turkish Language activities.

Furthermore, the ethnographic data also provided evidence that reading aloud sessions were often disregarded when any other activities taking place in the classroom were not completed. During these days, the observation was rescheduled with the classroom teachers.

\subsection{Pre-Reading (Set up)}

Almost half (9/17) of preschool classrooms were observed to have at least one pre-reading activity, and in the rest of the classrooms (8/17) no pre-reading activities occurred. The most common pre-reading activities in these nine classrooms included pointing to features of the book, such as the title, illustrations (8/9), talking about events and/or features to listen, look for in the book (4/9).

Further, in 3 classrooms the teachers discussed the concepts of print such as title, illustrator and in other 3 classrooms 
the teachers reminded the children of similar books they have read or that they have read same book before.

In less than a quarter (1/9) of the classrooms having pre-reading activities, the teacher related the book to the children's experiences outside of classroom activities.

\subsection{Reading}

During the observations, in the majority of the classrooms (13/17), reading experiences or activities were observed.

In almost every preschool classroom (12/13), the teachers used props (e.g., hand puppets, or classroom toy), dramatic voices and gestures during the reading aloud time. Further, they asked recall questions frequently about earlier parts of the books (12/13).

Also, during reading aloud time, some of the teachers (5/13) directed children's attention to illustrations and asked questions about the stories particularly when the whole group started to move around and did not pay attention to the books.

Furthermore, in 5 classrooms, the teachers highlighted new book-related vocabulary, at most 1 new vocabulary was introduced, but they did not offer information about the meaning of these book-related new vocabularies.

Similarly, only in 4 classrooms, the teachers asked book-related questions but they were not open ended questions which required prediction, expanded responses or thinking. The questions asked during the reading aloud time were only yes-and-no type questions that aimed children to recall some information about the book.

In some classrooms (4/13), the teachers answered only one to three children's questions about the book and they expanded on children's comments about the story plot or illustrations. During the observations, it was noted that when more than 2 to 3 children raised their hands and wanted to talk about the book, most of the time the teachers reminded that they had very little time left for the reading aloud time therefore the children had to wait for the next book reading session.

On the other hand, in 3 classrooms the children experienced no reading activities at all. The teachers read the text straight through the book. In these 3 classrooms, the teachers directed children to wash their hands and get ready for lunch time after each reading aloud session occurred.

\subsection{Post-Reading (Extension)}

In almost every classroom (15/17), after reading a book, the teachers asked for recall of information about the book. In some of the classrooms, the teachers answered the children's questions about the book and expanded children's comments, mostly on illustrations.

Some of the classrooms (5) observed to have the teachers summarized the story with child involvement. By contrast in other 5 classrooms, the teachers retold the story without child involvement.

On rare occasions, the teachers asked book-related open-ended questions. Only in 2 classroom the book-related open ended questions were observed; in one of them the teacher answered the question without waiting for the children's responses and in the other classroom, the teacher waited appropriate time for children to answer her question but the children did not respond at all. Interestingly, that teacher did not revise her question and ask again to get one or two possible answers.

Furthermore, there were no post-reading activities organized beyond oral discussion. In general, small number of books read to the children were related to the classroom theme or other activities in the class. Therefore, the teachers did not relate any of the book information to the classroom theme. Even if the books were related to the classroom themes, the themes were not always evident - for example, in charts, texts or posters - in classroom centers that might help children visualize and comprehend the concepts or vocabulary, and the books teachers read from were not accessible to the children for further reading or looking alone or in peer to peer shared reading time.

\subsection{Quality Indicators for OMLIT-RAP}

As mentioned in the method section, the RAP includes three quality indicators that summarizes particular aspects of the read-aloud: (1) the degree to which the adult introduces and contextualizes new vocabulary to support children's learning; (2) the extent to which the adult uses open-ended questions that invite children to engage in prediction, imagination, and/or rich description; and (3) the quality and length of any post-reading book-related activities that the adult organizes (beyond oral discussion).

Based on the results, in some of the classrooms (5) 1 or 2 story-related vocabulary words were introduced (for example, the teacher asked "have you ever heard the word "X"?), but no comprehension support was observed. In the collected data, there were very limited classroom reading aloud activities that aimed at developing the children's vocabulary and learning. The book-related new vocabulary support in the preschool classrooms was found to be of minimal quality. 
The findings also indicated that the adult use of open ended questions that invite children to think about the book in detail was minimal. During post-reading time, only 2 teachers used open ended questions about the book. However, one of the teachers did not provide opportunity for children to respond to question and the other teacher did not provide hints for children to think and respond her question. They did not consistently show interest in children's responses (for example, pausing for children, restating question when they did not understand it).

Further, the results displayed that the depth of post reading activities, - including answering children's questions about the book and expanding children's comments about the book, or asking for recall of information about the book, - to be of minimal to less than moderate quality. In almost every classroom, the post reading activities related to the book lasted less than 5 minutes.

\section{Discussion}

This study examined the quality of the reading alouds of 17 public preschool classrooms in Muğla, Turkey through detailed observations using the OMLIT-RAP, a description of teacher behavior when reading aloud to children under various categories. The results indicated the "read aloud profiles" of preschool classrooms - including pre-reading, reading and post-reading activities- to be of minimal-to-moderate quality.

Unsurprisingly, all the classrooms included sacks of books and reading areas; however, these areas, or the books in them, were in poor condition and unattractive to children. Indeed, none of the children were observed to show any interest in reading by choosing a book from the reading center and reading or pretending to read with their peers. In almost half of the preschool classrooms, no pre-reading activities of reading alouds were observed. The teachers alerted children to the reading activity and reading alouds started immediately after the teachers called without guiding book choice or reminding children of similar books they have read or that they have read same book before. Neither they talked about events or features to listen or look for in the book, nor did they narrate the story in advance of reading to make the reading alouds more appealing to the children. Although in the other half of the classrooms, pre-reading activities were observed, these activities were commonly limited to pointing to features of the book such as the title and illustrations, calling attention to the books they have read before and linking the book to the children's previous activities outside of class (for example, before reading a book on giraffes, the teacher reminded the visit they had to the zoo previously). These findings are in accordance with previous studies indicating that teachers do not spend sufficient time on pre-reading setting up activities and in general, reading alouds appear to be a stand-alone routine of the day without being part of other classroom activities or experiences (Damber, 2015) and suggest that in order to attract children's interests, reading areas need to be organized to be more physically and visually inviting to children (Justice, 2006; Kraemer, McCabe, \& Sinatra, 2012; Roskos \& Neumann, 2001; Tarım, 2015; Vukelich, Christie, \& Enz, 2012) and pre-reading activities should be intellectually stimulating.

Furthermore, in the data, almost the majority of the classrooms had reading activities during read alouds. The common reading activities appeared to be including using probs, dramatic voices and gestures; asking recall questions about earlier parts of the book. Also, during reading alouds, some of the teachers directed children's attention to illustrations and asked very brief yes-no questions. Similarly, only in small number of classrooms (4), the teachers asked book-related questions but they were not open ended questions which required prediction, expanded responses or thinking. The questions asked during the reading aloud time were only yes-and-no type questions that aimed children to recall some information about the book. These finding were not entirely unexpected, considering that previous studies reported that "for many teachers the greater hurdle is to successfully move more conversation during read-alouds to the inferential level because literal [brief] conversation is rather easy to elicit from children" (Zucker \& Landry, 2010, p. 83). Based on these findings, it may be suggested that teachers should ask book-related open ended questions and probe children's understanding by asking questions that require children to predict (e.g., what do you think will happen next?, what if...), elaborate responses and engage them in more thought-provoking conversations (Justice, Meier, \& Walpole, 2005; Zucker \& Landry, 2010).

As the previous studies emphasized children's vocabulary is supported when teachers provide rich explanations of words to children during read alouds in classrooms (Beck \& McKeown, 2007; Justice, Meier, \& Walpole, 2005). However, in the collected data, only in 5 classrooms, the teachers highlighted new book-related vocabulary, at most one new vocabulary was introduced in each read-aloud, but they did not define or give examples to help children understand unfamiliar words in the book. In similar line with the previous studies, this study also suggests that teachers should plan carefully and focus on multiple words or at least 1 or 2 in each read aloud session to develop children's vocabulary.

Unfortunately, in the collected data, there were no post-reading activities organized beyond oral discussion. This study extends support to the view that one of essential aspect of read-alouds in preschool classrooms include post-reading activities beyond oral discussion such as reinforcing book-related vocabulary through using drama, suggesting ways of extending activities (e.g., cooking foods from the story, acting out the characters from the book, creating similar 
spaceship from the book at science center) or offering literacy materials to draw or imitate writing their own books (Zucker \& Landry, 2010).

Based on the findings of this study, other ways of improving reading alouds in classrooms can be pinpointed, such as giving one or two vocabulary and accurate comprehension support for each word, having all children join in conversations with teachers during read alouds, expanding on children's comments about the book, placing the book in the context by mentioning the classroom theme or how the book fits into class activities and extending children's understanding by tapping into their own experiences to help them comprehend the story.

In keeping with a social-interactionist approach, a child's early literacy experiences should be understood as embedded within the context of their daily sociocultural environment. When read-alouds are in high-quality, they will enrich children's vocabulary (Beck \& McKeown, 2007; Justice, Meier, \& Walpole, 2005), develop print knowledge and phonological awareness (Mol, Bus, \& de Jong, 2009), and support oral language and early writing (Zucker and Landry, 2010).

If as researchers, we are to improve children's early literacy skills as a base for school readiness skills, we will need to ensure that teachers have a solid foundation in early literacy development and in aspects of oral language development as it relates to literacy. Teachers in early childhood education should need ongoing professional development to implement the curriculum objectives comprehensively and make improvements in their classroom practices.

\section{Implications and Future Directions}

The rapid increase in the number of children entering preschool necessitates the establishment of clear standards that go beyond physical infrastructure in order to assure that all children in Turkey receive a quality pre-primary education. The high quality reading alouds of the preschool classrooms play an important role in literacy development, as focusing on learning standards, particularly literacy experiences, skills and outcomes from an early age can contribute to the successful literacy development of children entering primary school.

Although this study provided valuable information on the current reading aloud profiles of public preschool classrooms in Muğla, due to the small sample size, the results should not be generalized to the population at large. Experimental studies examining the long-term effects of interventions in the classroom reading alouds on children's literacy growth and teacher trainings are being conducted by the author in preschool classrooms from different cities in Aegean part of Turkey but future research should be conducted with larger national samples to compare the preschool classroom read-alouds in different parts of Turkey in order to formulate national standards that can improve the quality of reading alouds in classrooms throughout the country.

\section{Acknowledgement}

This study has been presented at the VII. International Congress of Educational Research in Turkey, in May 2015.

\section{References}

Beck, I., \& McKeown, M. (2007). Increasing young low-income children's oral vocabulary repertoires through rich and focused instruction. The Elementary School Journal, 107, 251-271.

Damber, U. (2015). Read-alouds in preschool - A matter of discipline, Journal of Early Childhood Litearcy, 15, 256-280. http://dx.doi.org/10.1177/1468798414522823

Dickinson, D. K., \& Smith, M.W. (1994). Long-term effects of preschool teachers' book readings on low-income children's vocabulary and story comprehension. Reading Research Quarterly, 29, 104-122.

Dickinson, D. K., \& Tabors, P. O. (1991). Early literacy: Linkages between home, school, and literacy achievement at age five. Journal of Research in Childhood Education, 6(1), 30-46.

Dickinson, D., \& Brady, J. (2006). Toward effective support for language and literacy through professional development. In M. Zaslow \& I. Martinez-Beck (Eds.), Critical issues in early childhood professional development, 141-170.

Goodson, B. D., Layzer, C. J., Smith, W. C., \& Rimdzius, T. (2006). Observation Measures of Language and Literacy Instruction in Early Childhood (OMLIT). Cambridge, MA: Abt Associates, Inc.

Justice, L. M. \& Kaderavek, J. N. (2004). Embedded-Explicit Emergent Literacy Intervention I: Background and Description of Approach. Language, Speech, and Hearing Services in Schools, 35, $201-211$.

Justice, L. M. (2006). Evidence-based practice, response to intervention, and the prevention of reading difficulties. Language Speech and Hearing Services in Schools, 37, 284-297. http://dx.doi.org/10.1044/0161-1461(2006/033)

Justice, L. M., Meier, J., \& Walpole, S. (2005). Learning new words from storybooks: An efficacy study with at-risk kindergartners. Language, Speech, and Hearing Services in Schools, 36, 17-32. 
Kraemer, L., McCabe, P., \& Sinatra, R. (2012). The effects of read-alouds of expository text on first graders' listening comprehension and book choice. Literacy Research and Instruction, 51, 165-178. http://dx.doi.org/10.1080/19388071.2011.557471

Mol, S., Bus, A. G., \& de Jong, M. T. (2009). Interactive Book Reading in Early Education: A Tool to Stimulate Print Knowledge as well as Oral Language. Review of Educational Research, 79, 979-1007. http://dx.doi.org/10.3102/0034654309332561

Morrow, L.M. (1988). Young children's responses to one-to-one story readings in school settings. Reading Research Quarterly, 23, 89-107.

Morrow, L.M., \& Smith, J.K. (1990). The effects of group size on interactive storybook reading. Reading Research Quarterly, 25, 214-231.

Neuman, M. M., Hood, M., \& Ford, R. M. (2013). Using environmental print to enhance emergent literacy and print motivation. Reading and Writing, 26, 771-793. http://dx.doi.org/10.1007/s11145-012-9390-7

Neuman, M. M., Hood, M., Ford, R. M., Neumann, D. (2011). Using environmental print to enhance emergent literacy and print motivation. Journal of Early Childhood Literacy, 12(3), 231-258. http://dx.doi.org/10.1177/1468798411417080

Neuman, S. B., \& Cunningham, L. (2009). The impact of Professional development and coaching on early language and literacy instructional practices. American Educational Research Journal, 46(2), 532-566. http://dx.doi.org/10.3102/0002831208328088

Neuman, S. B., \& Dickinson, D. (Eds.). (2001). Handbook of early literacy research. New York, N.Y.: Guilford.

Neuman, S. B., \& Roskos, K. (1993). Access to Print for Children of Poverty: Differential Effects of Adult Mediation and Literacy-enriched Play Settings on Environmental and Functional Print Tasks. American Educational Research Journal, 30, 95-122. http://dx.doi.org/10.3102/00028312030001095

Roskos, K. A., Christie, J. F., Widman, S., \& Holding, A. (2010). Three decades in: Priming for meta-analysis in play-literacy research. Journal of Early Childhood Literacy, 10, 55-96. http://dx.doi.org/10.1177/1468798409357580

Roskos, K., \& Neuman, S. B. (2001). Environment and its influences for early literacy teaching and learning. In S. B. Neuman \& D. Dickinson (Eds.), Handbook of early literacy research, 281-294. New York: Guilford.

Sulzby, E., \& Teale, W. (1991). Emergent Literacy. In R. Barr, M. Kamil, P. Mosenthal, and P. D. Pearson (Eds.). Handbook of Reading Research Volume II, 727-758.

Tarım, Ş. D. (2015). Literacy environments of preschool education classrooms in Turkey: The case of Muğla. Journal of Education and Training Studies, 3(5), 264-271. http://dx.doi.org/10.11114/jets.v3i5.999

Vukelich, C., Christie, J., \& Enz, B. (2012). Helping young children learn language and litearcy: Birth through kindergarten (3rd ed.). Boston, MA: Pearson.

Vygotsky, L. S. (1978). The development of psychological processes. Cambridge, MA: Harvard University Press.

Whitehurst, G. J., \& Lonigan, C. J. (1998). Child development and emergent literacy. Child Development, 69(3), 848-872. http://dx.doi.org/10.1111/j.1467-8624.1998.tb06247.x

Zucker, A. T., \& Landry, S. H. (2010). Improving the quality of preschool read-alouds: Professional development and coaching that targets book-reading practices. In M. M. McKenna, S. Walpole, and K. Conradi (Eds.) Promoting Early Reading: Research, Resources and Best Practices, New York: The Guilford Press, 78-104.

\section{$(\mathrm{cc}) \mathrm{BY}$}

This work is licensed under a Creative Commons Attribution 3.0 License. 